\title{
EDITOR'S PREFACE TO THE NEW EDITION
}

Introduction to California Desert Wildflowers has introduced thousands to the wildflowers of the desert areas of California. Since it was first published in 1962, a number of plant names have been changed, and, in some cases, new information has been obtained. In this revised and updated edition, a number of steps have been taken to make the book current in content and appearance.

The first step was to review the selection of plants included. Philip Munz was most at home in the California deserts, and his expert knowledge of those regions is reflected in his original choices for inclusion in this field guide. After careful consideration we decided to retain Munz's original selections, without additions or eliminations.

Dr. Robert Ornduff wrote introductions to all four of the newly revised Munz wildflower books before his untimely death in 2000. His introduction to this volume describes the environmental factors that shape the desert habitat, and discusses some of the adaptive strategies that allow plants to survive in the harsh extremes of that setting.

Scientific names for each plant have been made to conform to the current California authority, the Jepson Manual: Higher Plants of California, J. Hickman, editor (University of California Press, 1993). In addition, almost every plant in this edition has been given a common name using the following 
sources, listed here in descending order of preference: the Jepson Manual; Philip Munz, California Flora (University of California Press, 1959); and Leroy Abrams, Illustrated Flora of the Pacific States (Stanford University Press, 1923-1960). Because some of the desert plants are not well known, occasionally it was necessary to consult additional sources (Philip Munz, A Flora of Southern California; and Willis Linn Jepson, A Manual of the Flowering Plants of California) to find an acceptable common name. In several instances there was no alternative but to use a proper name or surname in the common name, and in a few cases there simply was no common name found that would apply to the plant being described.

The rule developed by Munz for hyphenation has been used for all common names: If a plant's common name indicates a different genus or family, a hyphen is inserted to show that the plant does not actually belong to that genus or family. Thus, "skunk-cabbage" is hyphenated because the plant it refers to is not in the cabbage genus nor the cabbage family, but "tiger lily" is not hyphenated because the plant it refers to is in the lily genus, as well as the lily family. Within each color section the species accounts are arranged according to the same taxonomic order used by Munz in his original edition of Desert Wildflowers.

In the original edition of this guide, Munz called the two major deserts of California the Colorado Desert and the Mojave Desert. The new Jepson Manual no longer recognizes the Colorado Desert as a separate section of the larger Sonoran Desert, but to avoid any misinterpretation of Munz's original plant distribution accounts, this revised edition has retained the use of "Colorado Desert" as a more specific regional indicator.

Taking into account research done in the last 50 years, some species have been absorbed into other species, and some have been split into varieties or subspecies. Some varieties or subspecies have even become separate species. Each plant description has been carefully checked and revised or rewritten 
as needed for accuracy and currency. Some of the author's original language was out of date. An effort has been made to retain the Munz intent yet to make the new edition readable, entertaining, and informative to today's readers.

Diane Renshaw has brought the scientific names up to date and has made necessary and appropriate revisions and additions to the 1962 plant descriptions. The Press is grateful to her for her meticulous work. Many of the lively drawings of Jeanne Janish, mentioned in Munz's introduction, have been retained. New color illustrations and new design features have been added to make the book more user friendly. The Press is especially grateful to Jon Mark Stewart for sharing his outstanding collection of accurately identified color slides, many of which appear in this book, and for his patience in the revision process.

Many of the plants found in this book have had their range severely reduced by habitat destruction and disturbance and by invasive weeds. Users of this book are urged to respect all native plants and refrain from picking or collecting specimens. Please enjoy our unique flora, but leave it to flourish for future generations.

Phyllis M. Faber

April 2003 
